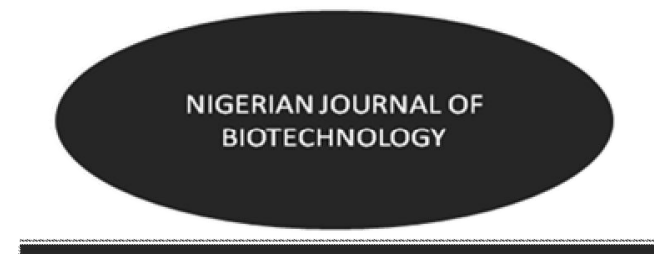

\title{
Prevalence and Antibiogram Profile of Salmonellae in I ntensively Reared and Backyard Chickens in Nsukka Area, Nigeria
}

\author{
Obi, O. J . and I ke, A. C. \\ Department of Microbiology, University of Nigeria, Nsukka, Enugu State
}

(Received 07:09:2015; Accepted 06:12:2015)

\begin{abstract}
Salmonellosis is a veterinary and public health problem of major importance. It is a leading cause of food poisoning in humans and an important cause of various diseases of livestock resulting in high morbidity and mortality. A cross sectional study was conducted to determine the prevalence of salmonellae in intensively reared and backyard chickens from poultry farms and markets across Nsukka environs, and to determine their antimicrobial susceptibility profiles. A total of $\mathbf{3 0 0}$ chickens comprising of $\mathbf{1 5 0}$ intensively reared and $\mathbf{1 5 0}$ backyard chickens were sampled by cloacal swab using International Office of Epizootics (OIE) standards. Out of 300 samples, 12 (4\%) were positive for salmonellae. Salmonellae prevalence rates of $1.3 \%$ in intensively reared and $6.7 \%$ in backyard chickens were observed. The prevalence rate of salmonellae was significantly higher $(P<0.05)$ in backyard chickens than in intensively reared chickens. The antibiogram studies showed that the Salmonella serovars were totally $(100 \%)$ resistant to amoxicillin and augmentin, moderately sensitive to nalidixic acid $(67 \%)$ and nitrofurantoin $(83 \%)$; and fully sensitive $(100 \%)$ to ciprofloxacin, ofloxacin, cotrimoxazole, and gentamicin. The MIC ranges for cotrimoxazole, ciprofloxacin, gentamicin, and tetracycline, were 8-16, 0.016-0.125, 0.5-1.0, and 2.0-8.0 $\mu \mathrm{g} / \mathrm{ml}$, respectively. MBC values of 0.031-0.5, 1.0-4.0, and $64.0-512.0 \mu \mathrm{g} / \mathrm{ml}$, were obtain for ciprofloxacin, gentamicin, and tetracycline, respectively. This study have shown that poultry birds harbour Salmonella spp. and could serve as reservoirs for the rare serotypes whose transmission vehicles remain unknown.
\end{abstract}

Key words: Salmonella spp., intensively reared chickens, backyard chickens, sensitive, resistant, antibiotics.

Correspondence: anthonyc.ike@unn.edu.ng

\section{Introduction}

Salmonellosis caused by Salmonella spp. is considered as a veterinary and public health problem of major importance, and one of the most prevalent diseases in birds, causing high losses in poultry industry, with a corresponding high socio-economic impact (Metawe and Tulip, 2004; Foley et al., 2008). It is a leading cause of food poisoning and foodbome illnesses in humans and therefore, a major public health concern (Shah and Korejo, 2012). In poultry, salmonellae give rise to pullorum diseases and fowl typhoid, resulting in increased mortality and poor quality in chicks hatched from infected eggs, anaemia, depression, laboured breathing and diarrhoea. In humans, salmonellosis results in enteric fever (typhoid) and acute gastroenteritis, which can range from mild to severe infection (Todar, 2005).

Most human cases of salmonellosis are thought to be linked to the consumption of products such as meat, poultry, eggs, milk, seafood, and fresh produce contaminated with the organism (Carrique-Mas and Davies, 2008; Foley et al., 2008). The organism's route of infection is the faecal-oral route via food or water contaminated with faeces or urine of previously infected persons or animals. Poultry birds have frequently been reported as a means of salmonellae contamination and most studies 
have implicated chicken carcasses and droppings (Orji et al., 2005; Payne et al., 2006; Fashae et al., 2010; Selvaraj et al., 2010; Hassanein et al., 2011). Nearly 2,500 Salmonella serovars are capable of infecting poultry and all are considered to be potentially pathogenic for man or animals (Al-Nakhli et al., 1999). Hence, monitoring and control of Salmonella in poultry has been a priority over the last few decades in developed countries (Eriksson and Aspan, 2007). In Nigeria there is a high rate of consumption of poultry products and increase in the cases of Salmonella-associated gastroenteritis has been frequently noticed (Fasure et al., 2012).

Most of the feed concentrates, consisting mainly of fish or meat meal, could be a potential source of Salmonella spp. and could serve as a means by which intensively reared poults could be infected. Backyard/free range chickens may be infected through contact with wild animals, domestic mammals, commercial poultry that are carriers of salmonellae, scavenging at the refuse tips and consequently may play a role in the transmission of the organism to other animals and humans.

The use of antimicrobials in any environment creates selection pressures that favour the survival of antibiotic-resistant pathogens (Adeleke et al., 2012). The routine practice of giving antimicrobials to domestic livestock for growth promotion and prophylaxis is an important factor in the emergence of antibiotic-resistant bacteria in the food chain (Akinyemi et al., 2007; Oluyege et al., 2010; Fasure et al., 2012; Shah and Korejo, 2012). The development of antimicrobial resistance among some of these pathogens has become a serious problem, especially the emergence of multi-drug resistant strains or variants. Some of these pathogens isolated from environmental sources have shown an increased resistance to antibiotics since they have developed a number of elaborate mechanisms for acquiring and disseminating plasmids, transposons, phages, and other genetic determinants (Harts and Kariuki, 1998). This study was undertaken to determine the prevalence of Salmonella spp. in chickens in Nsukka and its environs, and to determine the pattem of antimicrobial susceptibility of the isolates.

\section{Materials and methods}

Sample collection: A total of 300 cloacal swab samples comprising of 150 intensively reared chickens, collected from three different farms, and 150 backyard chickens, collected at three different live bird markets. The 150 backyard chickens were collected as follows: 50 from Nkwo Ibeagwa, 76 from I kpa and 26 from Eke Enugu-Ezike based on availability of local chicken for sampling, while 50 intensively reared chickens each were collected from Department of Animal Sciences, University of Nigeria, Nsukka (UNN) poultry, Faculty of Veterinary Medicine, UNN poultry and a private poultry farm in Nsukka town. The sample size was arrived at using a modified formula according to Abdullahi (2010). Samples were collected according to the recommendations of the International Office of Epizootics (OIE, 2012). Cloacal swab samples were collected from live birds using sterile cotton tipped swabs. The swab was inserted into the cloacae of each bird and rotated gently against the lining of the cloacae and immersed into a sterile tube containing $5 \mathrm{ml}$ of buffered peptone water (Lab M, Lancashire, United Kingdom). The collected samples were transported to the laboratory for further analysis within one hour from the time of collection.

$$
\text { Isolation and identification of }
$$

Salmonella isolates: The cloacal swab samples inoculated into the buffered peptone water were pre-enriched by incubating aerobically overnight at $37^{\circ} \mathrm{C}$. After incubation, $0.1 \mathrm{ml}$ of the overnight culture was transferred into $10 \mathrm{mls}$ of Rappaport Vassiliadis (RV) medium (Oxoid, Basingstoke, Hants, England) and incubated at $42^{\circ} \mathrm{C}$ for $24 \mathrm{~h}$. Thereafter, a loop-full of broth culture was streaked on Salmonella-Shigella agar (SSA) (Titan Biotech, India) and incubated aerobically for $24-48 \mathrm{~h}$ at $37^{\circ} \mathrm{C}$. Suspected colonies on the Salmonella-Shigella agar presenting as non-lactose fermenters, with or without hydrogen sulphide $\left(\mathrm{H}_{2} \mathrm{~S}\right)$ production were streaked on MacConkey agar (Micromedia Trading House, Torbagyi U, Hungary) for purity check and to obtain discrete colonies (Cheesbrough, 2006; Beyaz et al., 2010; Hemen et al., 2012). Suspected colonies of Salmonella were taken for further morphological and biochemical typing which included urease, triple sugar iron test, IMViC (Indole, Methyl red, Voges-Proskauer, Citrate), sugar fermentation tests, amino acid (lysine and arginine) 
decarboxylase, ONPG (orthonitrophenylgalactosidase), catalase, and motility. All biochemically typical Salmonella isolates were serotyped based on reaction with somatic (O), flagellar $(\mathrm{H})$, and capsular (Vi) antisera (Difco, USA). Salmonella $\mathrm{O}$ and Vi antigens were identified by slide agglutination test procedure. After the confirmation of the individual Salmonella $\mathrm{O}$ antisera, cultures were further characterized for $\mathrm{H}$ (phase $\mathrm{I}$ and II) antisera based on Spicer-Edwards antisera by tube test procedure. Serotyping was carried out at the WHO Collaborating Centre for Reference and Research on Salmonella at Pasteur Institut, Paris, France. The samples were shipped to France on Agar slants in a well packaged box containing ice packs.

Antibiotic susceptibility test:

Disc diffusion test: The antibiotic paper disc susceptibility test was performed according to the CLSI method (Kirby-Bauer disk diffusion test) on Muller-Hinton agar (Titan Biotech, India). About 3 to 4 discrete colonies of each isolate was inoculated into Mueller-Hinton broth separately and incubated for $24 \mathrm{~h}$ at $37^{\circ} \mathrm{C}$. The broths were matched to 0.5 McFarland standard and streaked using sterile cotton swabs on Mueller-Hinton Agar plates. The antimicrobial agents used were augmentin $(30 \mu \mathrm{g})$, ofloxacin $(5 \mu \mathrm{g})$, gentamicin $(10 \mu \mathrm{g})$, nalidixic acid (30 $\mu \mathrm{g})$, nitrofurantoin $(200 \mu \mathrm{g})$, cotrimoxazole (25 $\mu \mathrm{g})$, amoxicillin $(25 \mu \mathrm{g})$ and tetracycline $(25 \mu \mathrm{g})$ (Abtek Biologicals Ltd, Liverpool, United Kingdom). Pseudomonas aenuginosa ATCC 27853 served as control. Zones of inhibition were evaluated following the recommendations by CLSI, (2007).

MIC/MBC assay: The following antibiotics powder: (ciprofloxacin, gentamicin, tetracycline and sulphamethoxazoletrimethoprim combinations (cotrimoxazole)), were dissolved in appropriate diluents to obtain a stock solution of $5120 \mu \mathrm{g} / \mathrm{ml}$ each. Subsequent antibiotic dilutions were made in sterile Mueller Hinton broth and equal volume of the standardized inoculums was added to equal volume of an antibiotic concentration in test tubes. Antibiotic ranges were prepared one step higher than the final dilutions range required to compensate for the addition of an equal volume of inoculum (Andrews, 2001; CLSI, 2007). The inoculated tubes were incubated at $37^{\circ} \mathrm{C}$ for 16 $18 \mathrm{~h}$. Inoculated and uninoculated tubes of antibiotic-free Mueller Hinton broth and Pseudomonas aenuginosa ATCC 27853 served as controls. The MIC corresponds to the lowest concentration of antibiotic at which there is no visible growth of the organism. The MBC was determined by plating out the tubes that showed no sign of growth on antibiotic freeMueller Hinton agar plates and incubated at $37^{\circ} \mathrm{C}$ overnight (Andrews, 2001). The MBC corresponds to the lowest concentration of antibiotic that prevented the growth of the test isolates after subculture on antibiotic freeMueller Hinton agar plates.

\section{Results}

Out of the 300 cloacal swab samples analyzed, bacteriological examination revealed 12 strains of Salmonella. Overall, $4 \%$ prevalence rate was obtained in the two groups of chickens. Prevalence rates of $1.3 \%$ in intensively reared chickens and $6.7 \%$ in backyard chickens were observed. Highest Salmonella prevalence of $20.8 \%$ was observed for samples collected from Eke Enugu-Ezike market, while no Salmonella was isolated from samples collected from Faculty of Veterinary Medicine Poultry and the private poultry farm (Fig. 1). 


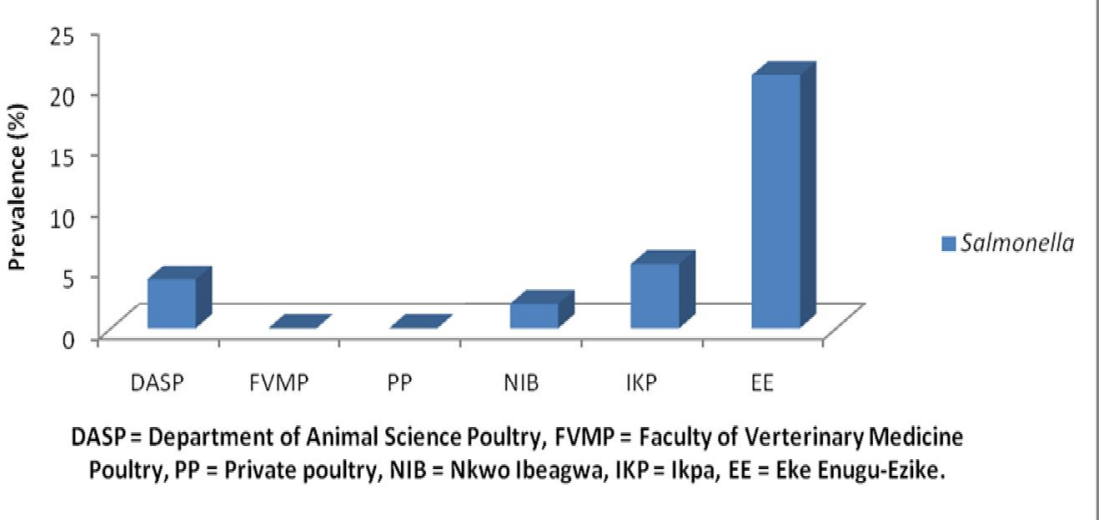

Fig. 1 Prevalence of Salmonella serovars based on sample source.

The antibiogram studies (Fig. 2) revealed that the Salmonella serovars were fully sensitive $(100 \%)$ to ofloxacin, gentamicin and cotrimoxazole, but totally resistant $(100 \%)$ to amoxicillin and augmentin. The general susceptibility pattem of the Salmonella serovar Enteritidis isolated from the intensively reared chickens and the backyard chickens to the antimicrobials showed approximately the same level of susceptibility (Fig. 3).

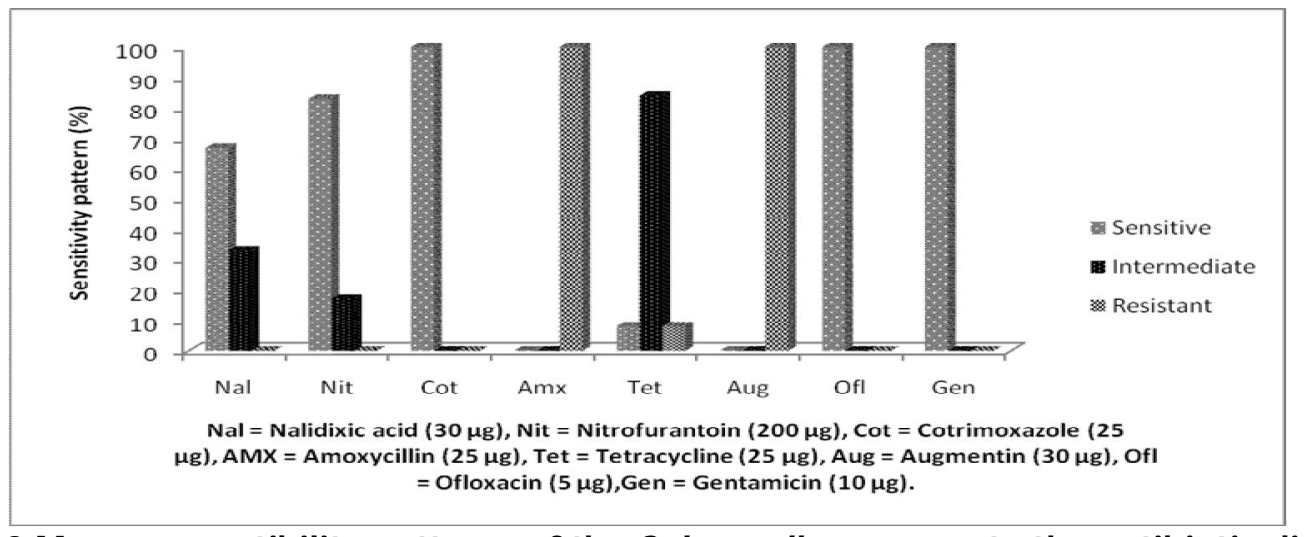

Fig. 2 Mean susceptibility patterns of the Salmonella serovars to the antibiotic discs.

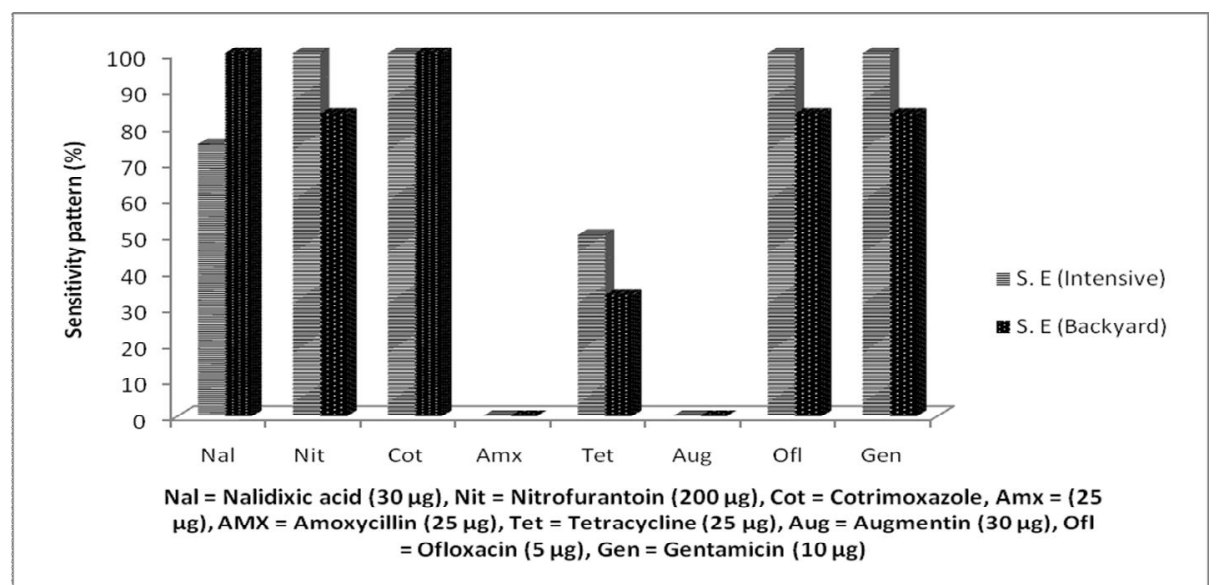

Fig 3 Comparison of mean susceptibility pattern of Salmonella ser. Enteritidis (S.E) isolated from intensively reared and backyard chickens. 
Table 1 shows the minimal inhibitory concentration and minimal bactericidal concentration of the antimicrobial agents on the Salmonella serovars. The MIC values for cotrimoxazole, ciprofloxacin, gentamicin and tetracycline range from $8.0-16.0 \mu \mathrm{g} / \mathrm{ml}, 0.016$ -
$0.125 \mu \mathrm{g} / \mathrm{ml}, 0.5-1.0 \mu \mathrm{g} / \mathrm{ml}$ and $2.0-8.0 \mu \mathrm{g} / \mathrm{ml}$ respectively. The MBC values for ciprofloxacin, gentamicin and tetracycline range from $0.063-$ $0.5 \mu \mathrm{g} / \mathrm{ml}, 1.0-4.0 \mu \mathrm{g} / \mathrm{ml}$ and $64.0-512 \mu \mathrm{g} / \mathrm{ml}$ respectively. Cotrimoxazole was not bactericidal on any of the isolate tested.

Table 1: MI C/ MBC values of the antibiotics tested against the Salmonella serovars

\begin{tabular}{llll}
\hline \multicolumn{1}{c}{ Antibiotics } & S. Enteritidis & $\begin{array}{c}\text { Test organisms MIC/MBC } \text { in }(\boldsymbol{\mu g} / \mathbf{m l}) \\
\text { S. Wangata }\end{array}$ & S. Penarth \\
\hline Cotrimoxazole & $8 / *$ & $8 / *$ & $16 / *$ \\
Ciprofloxacin & $0.125 / 0.125-0.5$ & $0.0156 / 0.063-0.125$ & $0.0313 / 0.5$ \\
Gentamicin & $0.5-1.0 / 1.0-2.0$ & $0.5-1.0 / 2.0-4.0$ & $1.0 / 1.0$ \\
Tetracycline & $2.0-4.0 / 128-512$ & $2.0-8.0 / 128-512$ & $2.0 / 64.0$ \\
\hline
\end{tabular}

* Not bactericidal

\section{Discussion}

Salmonellosis occurs worldwide in both developed and developing countries and is a major contributor to morbidity and mortality with resultant economic costs (Antoine et al., 2008). In the present study, bacteriological screening of samples (150 each from intensively reared chickens and backyard chickens) from apparently healthy chickens showed that 12 samples harboured Salmonella spp. I solation rate of $6.67 \%$ in backyard chickens was significantly higher $(p<0.05)$ than the $1.33 \%$ obtained from intensively reared chickens. The low rate of salmonellae isolation observed in intensively reared chickens could be attributed to improved hygienic conditions in the poultry environment, and possibly, the incorporation of antimicrobials in poultry feeds.

Similar rate of salmonellae isolation $(2 \%)$ in intensively reared chickens was reported in northem Thailand by Hanson et al. (2002). Isolation rate obtained in the present study was higher compared to $0 \%, 0.8 \%$ and $0.83 \%$ rates reported by Curtello et al. (2013) in Jamaica, Aragaw et al. (2010) in Ethiopia and Ammar et al. (2010) in Algeria respectively. The direct plating out method of the samples without enrichment and improved poultry hygienic conditions reported in these studies could have contributed to the lower rates. The prevalence rate of salmonellae obtained in intensively reared chickens in the present study was lower than the prevalence rates of $4.9 \%, 12.4 \%$, $19 \%, 71 \%$ and $84 \%$, reported by Saad et al. (2007) in Saudi Arabia, Ibrahim et al. (2013) in
Egypt, Al-Abadi and Al-Mayar (2012) in Iraq, Ahmed et al. (2008) in Bangladesh, Ramya et al. (2012) in India, respectively. The observed high rates of salmonellae isolation in these studies could be as a result of the selective enrichment protocol employed in the studies and the geographical distribution where unhygienic conditions may have contributed to the high rates. Additionally, cloacal swabs from only diarrheic birds were analyzed in most of the studies with high prevalent rates. A lower rate of isolation $(2.5 \%)$ of salmonellae in backyard (free range) chickens has been reported by Salihu et al. (2014) in Nasarawa, Northem, Nigeria.

Salmonellae were only isolated in one out of the three farms in the present study. This could be attributed to the incorporation of antimicrobials in poultry feeds, intermittent shedding of the salmonellae, or maintenance of good hygiene in the poultry environment. A similar pattem of isolation has been reported in Ethiopia by Aragaw et al. (2010) who failed to isolate Salmonella spp. in two of the three farms visited and also by Curtello et al. (2013) in Jamaica who failed to isolate Salmonella spp. from 1500 cloacal swab samples across different farms.

The routine practice of giving antimicrobials to domestic livestock for growth promotion and prophylaxis is an important factor in the emergence of antibiotic-resistant bacteria in the food chain (Su et al., 2004; Shah and Korejo, 2012). Hence, in recent years, antibiotic resistance in Salmonella has assumed alarming proportions worldwide (Murugkar et al., 2005). 
Monitoring drug resistance pattem among the isolates not only gives vital clues to the clinicians and farmers regarding therapeutic regime to be adopted against individual cases, it is also an important tool to devise a comprehensive chemoprophylactic and chemotherapeutic drug schedule on flock basis within a geographical area.

Antimicrobial susceptibility test revealed that the Salmonella serovars isolated in the present study were $100 \%$ resistant to amoxicillin and augmentin; slightly resistant to tetracycline $(8 \%)$, and highly sensitive to nalidixic acid, nitrofurantoin, cotrimoxazole, gentamicin, and the fluoroquinolones (ofloxacin and ciprofloxacin). The MIC values obtained for cotrimoxazole, ciprofloxacin, gentamicin, and tetracycline lie within the equivalent sensitive MIC breakpoint range. The combination trimethoprim/sulphamethoxazole

(cotrimoxazole) was not bactericidal on the Salmonella serovars, whereas ciprofloxacin and gentamicin exhibited bactericidal activities. Generally, the tetracycline MBC values far exceeded the MIC values (fourfold increase) which is probably due to its bacteriostatic nature. The Salmonella serovars were classified as multidrug resistant (MDR) being resistant to more than one antibiotic. The total resistant pattern for augmentin and amoxicillin by the salmonellae obtained in this study could also be attributed to long over use of these agents and related compounds in poultry feeds and or abuse by the local populace.

The antimicrobial sensitivity pattem obtained in this study agrees with the reports of Ogunleye et al. (2005) on increased susceptibility of Salmonella Paratyphi isolated from a commercial poultry farm in Ibadan to gentamicin and moderate sensitivity to nitrofurantoin and tetracycline; but varies with the report on augmentin being moderately sensitive and resistance to nalidixic acid. Our results are in total disagreement with the reports of Salihu et al. (2014) that reported a high resistance ( $81.7 \%$ ) to ciprofloxacin, $76.1 \%$, $65.8 \%, 66.2 \%, 58.1 \%$, and $12.9 \%$ to gentamicin, ampicillin, chloramphenicol, cotrimoxazole, and amoxicillin, respectively. This could be due to differences in the strains of bacteria in the two studies and to environmental differences. They also vary with the reports of Murugkar et al. (2005) in India that reported moderate sensitive to amoxicillin by the Salmonella serotypes. The variation between the susceptibility patterns to amoxicillin could be attributed to increase resistance to the $\beta$ lactams and/or environmental variations.

In conclusion, the findings of this study show that poultry birds may be asymptomatic carriers and shedders of pathogenic bacteria in their faeces, thereby contaminating the environment. Any prophylactic program aimed at controlling these agents in poultry farms, must take into account backyard/free range chickens.

\section{Acknowledgements}

Authors are very thankful to Dr. Simon Le Hello, Co-directeur Centre National de Référence E. coli/Shigella/Salmonella Institut Pasteur, for serotyping of the isolates, and also to $\mathrm{Dr}$. Oladepo Dauda of the National Institute for Pharmaceutical Research and Development (NIPRD), Abuja for providing the reference Pseudomonas aeruginosa (ATCC 28573) isolate.

\section{References}

Adeleke, M. A., Akatah, H. A., Hassan, A. O. and Adebimpe, W. O. (2012). Microbial Load and Multiple Drug Resistance of Pathogenic Bacteria Isolated From Feaces and Body Surfaces of Cockroaches in an Urban Area of Southwestern Nigeria. J. Microbiol. Biotechnol. Food Sci. 1: 1448-1461.

Ahmed, A. K. M., Islam, M. T., Haider, M. G. and Hossain, M. M. (2008). Seroprevalence and pathology of naturally infected Salmonellosis in poultry with isolation and identification of causal agents. J. Bangladesh Agr. Univ. 6: 327334.

Akinyemi, K. O., Bamiro, B. S. and Coker, A. O. (2007). Salmonellosis in Lagos, Nigeria: Incidence of Plasmodium falciparum-associated co-infection, pattems of antimicrobial resistance and emergence of reduced susceptibility to fluoroquinolones. J. Health Popul. Nutr. 25: 531538.

Al-Abadi, I. K. M. and Al- Mayah, A. A. S. (2012). I solation and identification of Salmonella spp. from chicken and chicken environment in Basrah province. Iraqi Acad. Sci. J. 2: 88-99. 
Al-Nakhli, H. M., Al-Ogaily, Z. H. and Nassar, T. J. (1999). Representative Salmonella serovars isolated from poultry and poultry environments in Saudi Arabia. Sci. Tech. Rev. (OIE) 18: 700709.

Ammar, A., Nadir, A., Omar, B. and Ahmed, K. (2010). Survey of Salmonella serovars in broilers and laying breeding reproducers in Eastem Algeria. J. Infect. Dev. Countries 4: 103-106.

Andrews, J. M. (2001). Determination of minimum inhibitory concentrations. J. Antimicrob. Chemoth. 48: 5-16.

Antoine, S. T., Annaelle, K. and Anne, B. (2008). Epidemiological analysis of Salmonella enterica from beef sampled in the slaughter house and retailers in Dakar (Senegal) using pulsed-field gel electrophoresis and antibiotic susceptibility testing. J. Food Microbiol. 123: 191-197.

Aragaw, K., Terefe, L. and Abera, M. (2010). Prevalence of Salmonella Infection in Intensive Poultry Farms in Hawassa and Isolation of Salmonella species from sick and dead chickens. Ethiopian Vet. J. 14:115-124.

Beyaz, L., Atasever, A., Aydin, F., Gümüşsoy, K. S. and Abay, A. (2010). Pathological and clinical findings and tissue distribution of Salmonella Gallinarum infection in turkey poults. Turkish J. Vet. Anim. Sci. 34: 101-110.

Carrique-Mas, J. J. and Davies, R. H. (2008). Sampling and bacteriological detection of Salmonella in poultry and poultry premises: a review. Sci. Tech. Rev. (OIE) 27: 665-667.

Cheesbrough, M. (2006). District Laboratory Practice in Tropical Countries. $2^{\text {nd }}$ Edition. University Press, Cambridge. Pp: 62-74.

CLSI (Clinical and Laboratory Standard Institute) M100-S17. (2007). Performance standards for antimicrobial susceptibility testing; Seventeenth informational supplements. (Clinical and Laboratory Standards Institute, Pennsylvania.

Curtello, S., Vaillant, A., Asemota, H., Akpaka, P. E. and Smikle, M. P. (2013). Prevalence of Salmonella Organisms in Poultry and Poultry Environments in Jamaica. British Microbiol. Res. J. 3: $461-469$.
Eriksson, E. and Aspan, A. (2007). Comparison of culture, ELISA and PCR techniques for Salmonella detection in faecal samples for cattle, pig and poultry. BMC Vet. Res. J. 3: 1-19.

Fashae, K., Ogunsola, F., Aarestrup, F. M. and Hendriksen, R. S. (2010). Antimicrobial susceptibility and serovars of Salmonella from chickens and humans in Ibadan, Nigeria. J. Infect. Dev. Countries 4: 484-494.

Fasure, A. K., Deji-Agboola, A. M. and Akinyemi, K. O. (2012). Antimicrobial resistance pattems and emerging fluoroquinolone resistant Salmonella isolates from poultry and asymptomatic poultry workers. Afr. J. Microbiol. Res. 6: 2610-2615.

Foley, S. N., Lynne, A. M. and Nayak, R. (2008). Salmonella challenges: Prevalence in swine and poultry and potential pathogenicity of such isolates. J. Anim. Sci. 86: E149-E162.

Hanson, R., Kaneene, J. B., Padungtod, P., Hirokawa, K. and Zeno, C. (2002). Prevalence of Salmonella and E. coli, and their resistance to antimicrobial agents, in farming communities in northem Thailand. SE Asian J. Trop. Med. Pub. Health 33: 120-126.

Harts, C. A. and Kariuki, S. (1998). Antimicrobial resistance in developing countries. Brit. Med. J. 37: 647-650.

Hassanein, R., Hassan Ali, S. F., Abd El-Malek , A. M., Mohamed, M. A. and Elsayh, K. A. (2011). Detection and identification of Salmonella species in minced beef and chicken meats by using Multiplex PCR in Assiut city. Vet. World 4: 5-11.

Hemen , J.T., J ohnson, J.T., Ambo, E.E., Ekam, V.S, Odey, M.O. and Fila, W.A. (2012). MultiAntibiotic Resistance of Some Gram Negative Bacterial Isolates from Poultry Litters of Selected Farms in Benue State. Int. J. Sci. Technol. 2: 543-548.

Ibrahim, M. A., Emeash, H. H., Ghoneim, N. H. and Abdel-Halim, M. A. (2013). Seroepidemiological studies on poultry salmonellosis and its public health importance. J. World Poult. Res. 3: 18-23. 
Metawe, Y. F. and Tulip A. A. (2004). Epidemiological Studies on Salmonellae in Poultry Feed Mills. Benha Vet. Med. J. 15: 134146.

Murugkar, H. V., Kumar, R. A. and Bhattacharyya, D. (2005). Isolation, phage typing \& antibiogram of Salmonella from man \& animals in northeastem India. Indian J. Med. Res. 122: 237-242.

Ogunleye, A. O., Ajuwape, A. T. P., Adetosoye, A., Alaka, O. O. and Emikpe, B. O. (2005). Outbreaks of Salmonella paratyphi $A$ in a commercial poultry farm in Ibadan, Nigeria. Trop. Vet. 23: 65-68.

O.I.E (Intemational Office of Epizootics) Terrestrial Manual (2012). Fowl typhoid and pullorum disease. http://www.oie.int/fileadmin/home/eng/health... 22.03.11 fowl typhoid.pdf. Retrieved on 23rd J anuary, 2013.

Ojo, O. E., Ogunyinka, O. G., Agbaje, M., Okuboye, J. O., Kehinde, O. O. and Oyekunle, M. A. (2012). Antibiogram of Enterobacteriaceae isolated from free-range chickens in Abeokuta, Nigeria. Vet. Arhiv 82: 577-589.

Oluyege, J.O., Olaleye, A.J and Oluyege, A.O. (2010). Antibacterial effect of some Nigerian medicinal plants on drug- resistant Salmonella species isolated from environmental sources. Continental J. Microbiol. 4: 25-30.

Orji, M. C., Onuigbo, H. C. and Mbata, T. I. (2005). Isolation of Salmonella from poultry droppings and other environmental sources in Awka, Nigeria. Int. J. I nfect. Dis. 9: 86-89.

Payne, J. B., Li, X., Santos, F.B.O. and Sheldon, B. W. (2006). Characterization of Salmonella from Three Commercial North Carolina Broiler Farms. Int. J. Poult. Sci. 5: 1102-1109.
Ramya, P., Madhavarao, T. and Rao, L. V. (2012). Study on the incidence of Salmonella enteritidis in poultry and meat samples by cultural and PCR methods. Vet. World 5: 541545.

Saad, A. M., Almujali, D. M., Babiker, S. H., Shuaib, M. A. M., Abdelgadir, K. A. and Alfadul, Y. A. (2007). Prevalence of Salmonellae in broiler chicken carcasses and poultry farms in the central region, K.S.A. J. Anim. Vet. Advan. 6: 164-167.

Salihu, A. E., Onwuliri, F. C. and Mawak, J. (2014). Antimicrobial resistance profiles of Salmonella gallinarum isolates from free-range chickens in Nasarawa state, Nigeria. Int. J. Bacteriol. Res. 2: 019-027.

Selvaraj, R., Das, R., Ganguly, S., Ganguli, M., Dhanalakshmi, S. and Mukhopadhayay, S. K. (2010). Characterization and antibiogram of Salmonella spp. from poultry specimens. J. Microbiol. Antimicrob. 2: 123-126.

Shah, A. H. and Korejo, N. A. (2012). Antimicrobial Resistance Profile of Salmonella Serovars Isolated from Chicken Meat. J. Vet. Anim. Sci. 2: 40-46 (2012).

Su, L. H., Chiu, C. H., Chu, C. and Ou, J. T. (2004). Antimicrobial resistance in non typhoid Salmonella serotypes: A global challenge. Clin. Infect. Dis. 39: 546-551.

Todar, K. (2005). Salmonella and salmonellosis. Todar's Online Textbook of Bacteriology. University of Wisconsin-Madison, Department of Bacteriology.

http://www.textbookofbacteriology.net. Retrieved on $18^{\text {th }}$ J anuary, 2013. 